\title{
Policy Implications of Droughts and Floods Adaptation on Household Crop Production and Food Security in Southern Malawi
}

\author{
Phirilnnocent Pangapanga ${ }^{1 *}$, Charles BL. Jumbe ${ }^{2}$, Shelton Kanyanda ${ }^{3}$ \\ and Lucy Thangalimodzi ${ }^{4}$ \\ ${ }^{1}$ Integrated Surveys on Agriculture, National Statistical System, Zomba, Malawi. \\ ${ }^{2} C A R D$, Bunda College, Lilongwe, Malawi. \\ ${ }^{3}$ National Statistical System Coordinator, National Statistical Office, Zomba, Malawi. \\ ${ }^{4}$ Research for Development (RfD), Lilongwe, Malawi.
}

\begin{abstract}
Authors' contributions
This work was carried out in collaboration between all authors. PP designed the study, performed the statistical analysis, wrote the protocol, and wrote the first draft of the manuscript. CBLJ and SK managed the analyses of the study. $L T$ managed the literature searches. All authors read and approved the final manuscript.
\end{abstract}

Research Article

Received $15^{\text {th }}$ August 2012

Accepted $15^{\text {th }}$ September 2012

Published $6^{\text {th }}$ October 2012

\section{ABSTRACT}

Aims: This paper quantified the contribution of drought and flood related adaptation strategies on household food production and food security.

Place and Duration of Study: It was conducted in lowland and highland areas of southern Malawi and data was collected from randomly sampled households using a semi-structured questionnaire.

Methodology: The paper employed a Translog production function and a Tobit model to determine the effects of drought and flood related adaptation strategies on food production and food security. About 1000 households were randomly selected to participate in the household survey. Fifty percent of the respondents were from lowland areas while the remaining $50 \%$ was from highland areas of Southern Malawi.

Results: Results show that households in the study area adapted through irrigation farming, income-generating activities, crop diversification and shifting planting dates. Irrigation farming significantly increased food production by $8 \%$ and $6 \%$ and improved 
food availability by $24 \%$ and $19 \%$ in low and highland areas, respectively $(\mathrm{p}<0.05)$. On the other hand, shifting crop-planting dates reduced food production by $24 \%$ and $37 \%$ and food availability by $20 \%$ and $11 \%$ at $5 \%$ level of significance in low and highland areas, respectively.

Conclusion: This paper concluded that adaptation strategies have very interesting and significant policy implications on household crop production and food security. It is therefore suggested that decisions by policy/decision makers on household food production and availability should strive at mainstreaming droughts and floods related adaptation.

Keywords: Normalized tobit model; translog production function; food security; droughts and floods; adaptation strategies.

\section{INTRODUCTION}

Malawi, with a population of 14 million and a gross domestic product of about US $\$ 5$ billion, is one of the third world countries that are heavily dependent on agriculture (IMF, 2011). Presently, food productivity does not meet the food demand due to, in part, deteriorating soil productivity that has been exasperated by droughts and floods (Action Aid International, 2006). Reduced soil productivity, crop failures and damages have negatively affected the agricultural sector. On the other hand, agriculture in Malawi forms the mainstay of the economy and constitutes the primary source of livelihood for the overwhelming growing population. It contributes about $35 \%$ to gross domestic product. Approximately $85 \%$ of household derive food and nutritional security from agriculture (World Bank, 2010).

Droughts and floods have worsened the agricultural sector through reduced household crop production and food security. Droughts and floods have been major causes of the country's fluctuating and deteriorating household crop production and food security since early 1990s. In $1997-1998$, food production reduced by $3.1 \%$ followed by $3.5 \%$ drop in $2000-2001$. About $10 \%$ decline in food production was reported in 2004-2005. In 2008, about 1.1 million people, on average 242,000 households, were food insecure due to extreme events such as droughts (Action Aid International, 2006; GoM, 2004; Tchale et al., 2004). NSO 2012 reported that more than $40 \%$ of the population in Malawi is food insecurity. Around, $58 \%$ of the population in Southern Malawi, in 2010-2011, experienced reduced food production due to, in parts, droughts and floods (NSO, 2012). In Chikhwawa district alone, 75 percent of the households faced food shortages. Out of these households, more than half of the households attributed droughts and floods as major causes of low household food production and high food insecurity.

Following the impacts of droughts and floods on household crop production and food security, the Malawi government, nongovernmental organizations and individual households have developed a number of adaptation strategies to contain the effects of droughts and floods (GoM, 2008). Some of the adaptation strategies developed and introduced includes irrigation farming, income generating activities, crop diversification and shifting planting dates. Although the impacts of droughts and floods on household crop production and food security are widely recognized (Pangapanga et al., 2012), little is known about what is the impact of adaptation on household crop production and food security (Pangapanga et al., 2012; Gomani et al., 2008; Action Aid International, 2006). It is empirically proven that research on household adaptation to droughts and floods offers better policy options on how 
to integrate adaptation strategies in droughts and floods projects (Aggarwal et al., 2010). This paper therefore examines strategies that have greater economic impacts on household crop production and food security. It further unpacks scenarios where farmers adapt at least one strategy in reducing the effects of droughts and floods in Southern Malawi. Through application of Translog production and Tobit model, this paper isolates significant roles that adaptation plays at household level in terms of enhancing crop production and household food security.

\section{LITERATURE REVIEW}

A number of studies have been conducted in Sub Sahara Africa on natural disasters (droughts and floods), adaptation and food production. However, most studies have concentrated on the impacts of droughts and floods on food production and less on the impacts of adaptation strategies (Aggarwal et al., 2010; Akpalu et al., 2008; Hassan and Nhemachena, 2008). Action Aid International (2006) assessed farmers' adaptation towards droughts and floods in Southern part of Malawi. It was found that most households in Malawi do not have sufficient capacity to cope with challenges posed by droughts and floods. However, the study did not estimate the impacts of adaptation strategies on household food production and food security. Pauw et al., (2009) used a general equilibrium model to study the impacts of drought and floods on economy-wide in Malawi. Empirical results showed that droughts and floods were associated with loses of $1.7 \%$ in Gross Domestic Product. It was recommended that adaptation strategies have to be intensified in order to counteract the adverse impacts of droughts and floods. Studies conducted by Nangoma (2007) and EAD (2006) identified improved varieties, irrigation farming, shifting cropping dates and crop diversification as some of the household adaptation strategies to droughts and floods in the Southern Malawi.

Langyintuo and Mekuria (2008) used a Tobit model to analyse the effects of household characteristics on adoption of improved varieties among Mozambican farmers. The study found a significant contribution of social networks to technology adoption. It was suggested that government should invest in farmers' associations to facilitate high technology adoption. Kato et al.(2009) studied the impacts of soil and water conservation on crop production using a Cobb-Douglas function in the low and high rainfall areas of Ethiopia. The results showed a significant contribution of soil and water conservation on household food production. For instance, it was found that soil and water conservation technologies increased production by $4 \%$ and $25 \%$ between the low and high rainfall area, respectively. Besides, it was reported that grass trip improved production by $32 \%$ and $15 \%$ between the low and high rainfall areas, respectively. Kato et al., 2009 also found that irrigation increased production by $4 \%$ among low rainfall areas while a $25 \%$ reduction in food production among highland households. These results suggest that soil and water technologies performed differently in different agro-ecological of Ethiopia. This underscored the importance of geographical targeting when promoting and scaling up soil and water conservation technologies.

Most studies have proposed specific studies and technologies to address droughts and floods impacts and household adaptation in specific locations (Aggarwal et al., 2010; Kato et al., 2008; Deressa, 2006). Studies conducted in Malawi have mainly assessed the impacts of droughts and floods on food production and food security (Action Aid International, 2006; Gomani et al., 2007). According to literature reviewed, no study has been conducted to assess roles of adaptation strategies on food production and food security in Malawi. This study employs a Translog production and Tobit models to examine the impacts of adaptation 
strategies on food production and food security in low and highland ${ }^{1}$ of Chikhwawa, respectively.

\section{METHODOLOGY}

\subsection{Contribution of Adaptation on Household Food Crop Production}

Food production depends on a number of resources that can be transformed into output. It is illustrated in a more general quantitative description over various technical production possibilities as equation 1, where $W_{r}$ is the yield per hectare, $G_{r}$ is a vector of factor of production (land, labour and seeds), $\varsigma$ is a vector of unknown parameters to be estimated and $Y_{i}$ is an error term. Production function can be estimated by either parametric stochastic frontier or non parametric methods (Farrell, 1957; Chavas and Cox, 1988). The stochastic approach is subject to prior decisions on the modelling of the underlying technology and is specified by adhering to theory as well as flexibility (Tchale and Sauer, 2006). Following Aigner et al. (1977), food production function takes on a truncated normal distributed error term. Parametric analysis is appropriate and allows for error term which includes factors that affect food production but are outside farmers' control (Bauer, 1990). Food production function model can be re-specified as follow:

$$
W_{r}=f_{r}(G, \varsigma, D, \Gamma, \varrho)+\gamma_{r}
$$

Where , $\Gamma$ and denote vectors of unknown parameters to be estimated. $D_{r}$ is a dummy variable for adaptation strategies to droughts and floods. $D_{r}=1$ if the household adopt a specific strategy and $D_{r}=0$ if otherwise. Several production functions such as Cobb Douglas, Quadratic, Square Root and Translog have been used to estimate the parameters of factors of production. The choice of these production functions depends on the researcher, paper objectives and others (Bravoureta and Reiger, 1991). In this paper, a ricardian model is chosen to estimate farm level production. The model is developed to explain the variation in land value per hectare. Generally, the impacts of droughts and floods are reflected by measuring a reduction in net revenue. Since the response is nonlinear, a quadratic functional form has widely been used and it uses both linear and a quadratic term for all climatic variables introduced (Aigner et al., 1977; Tchale and Saure, 2006). It also assumes that the expected impact of variables on farm net revenue is evaluated at the mean and is specified as follows:

$$
W_{r}=\varrho+\varsigma G_{r}+\varsigma G_{r}^{2}+\Gamma D_{r}+\gamma_{r}
$$

where,$\Gamma$ and are vectors of unknown parameters and other variables are as explained above. The quadratic function form has nevertheless received several criticisms over yield response plateauxity (Bravoureta and Reiger, 1991). In this paper, a normalized Translog form of the quadratic function is applied. A normalized Translog model is widely used for describing the crop response to factors of production. Following Tchale and Sauer (2006), the paper adopts the Translog production function because of its flexibility and convenience to the researcher. The Translog production function is further chosen because it can easily

${ }^{1}$ Lowland households are those households that have gardens with altitude below 80 meters and situated along $16^{\circ} 16^{\prime} 08.80 \mathrm{~S} 34^{\circ} 58^{\prime} 33.01 \mathrm{E}$ while highland households are those households with altitude above 80 meters and located along $15^{\circ} 57^{\prime} 14.06^{\prime} S 34^{\circ} 45^{\prime} 53.92 \mathrm{E}$ ) 
incorporate variables that are not restrictively to factors of production (Tchale and Saure, 2006). The following analysis uses a primal production function other than the dual profit function as the latter is conditioned on prices. However, a robust Translog production function is used to give efficient and consistent estimates without endogeneity being a major problem. We specify our Translog production function as follows:

$$
\ln W_{r}=\varrho+\varsigma \ln G_{r}+\varsigma \ln G_{r} D_{r}+\Gamma D_{r}+\gamma_{r}
$$

From equation [3], all variables are normalized to the sample mean by dividing by the mean value. The marginal product of input $r$ is obtained by multiplying the logarithmic marginal product with the average product of input $r$. Thus the monotonicity holds if equation (21) is true for all inputs.

$$
\frac{d w}{d G_{r}}=\frac{w d \ln w}{G_{r} d \ln G_{r}}=\frac{w}{G_{r}}\left[\varrho+\varrho \ln G_{r}\right]>0
$$

By further adhering to the law of diminishing marginal productivities, marginal products should be decreasing in inputs. This implies the fulfillment of the following equation:

$$
\frac{d^{2} w}{d G_{r}^{2}}=f_{r}=\left(\frac{w}{G_{r}^{2}}\right)\left[\left(\varrho+\varrho \ln G_{r}\right)\left(\varrho-1+\varrho \ln G_{r}\right)\right]<0 ; f_{r}=f_{1}, f_{2}, \ldots f_{N}
$$

Quasi-concavity conditions are related to the fact that this property implies a convex input requirement set. With respect to the Translog production function curvature depends on the specific input bundle $G_{r}$. The condition of negative semi-definiteness of the bordered Hessian (BH) is met only locally (Tchale et al., 2004). The respective $\mathrm{BH}$ is negative semidefinite if the determinants of its entire principal are alternate in sign.A household maximizes net revenue on food production by moving towards diversified cropping. $W_{r}$ takes on net revenues from crops such as maize, millet and sorghum in the same year. A Normalized Translog production function is presented as follows:

$$
\ln p W_{r}=\varrho+\varsigma \ln G_{r}+\varsigma \ln G_{r} D_{r}+\Gamma D_{r}+\gamma_{r}
$$

Where $\mathrm{p}$ is the price of each of the crops per kilogram, $W_{r}$ is the yield per acre while , and Гdenote unknown parameters to be estimated. Since prices did not vary significantly, total crop yield were used as a dependent variable to determine the effect of climatic variables on food production.

\subsection{Contribution of Adaptation on Household Food Security}

Food security is a situation where all household members have adequate food throughout the year. In Malawi, households are considered food secure if each household member has at least $300 \mathrm{~kg}$ food per year (GoM, 2008). The paper assumes that $300 \mathrm{~kg}$ per year person of the food crop produced is a threshold. Any household that has more or equal to $300 \mathrm{~kg}$ per person per year is food secure and not otherwise. This threshold assumption allows us to adopt a censored data-modelling criterion. One of the censoring regressions is a Tobit model which illustrates the relationship between non negative variable $Q_{l}$ and independent variables $H_{l}$. In this paper, $Q_{l}$ and $H_{l}$ denote quantity of available food and vector of household characteristics, respectively. This model assumes that there is a latent dependent variable. 
Practically, a household food security is not only achieved through own production but also through economic or market based food accessibility. Food security can be further defined as total food availability at household level. Total food availability at household is however affected by a number of household specific and other non observable characteristics. Household characteristics range from economic to environmental. Mathematically, latent model is simplified as follows:

$$
Q_{l}=f_{l}(H, M)+\kappa_{l}
$$

where $Q_{l}$ is total food availability at household level and is equal to zero if the household has total food available of less than $300 \mathrm{~kg}$ per person per year. $Q_{l}$ equals the actual total food available amount if the household has food of more than or equal to $300 \mathrm{~kg}$ per person per year. $M_{l}$ denotes a vector of adaptation strategies, respectively. $M_{l}=1$ if the household adapt to changes in climate and $M_{l}=0$ if otherwise. $\kappa_{l}$ is a vector of non observable characteristics. Since equation [7] censors some data, we call it a Tobit model. A Tobit Model has the characteristics of assessing the contribution of adaptation strategies towards food security. In other words, each person at household level is food secure if they have at least $300 \mathrm{~kg}$ per year. The Tobit model is chosen because it ably censor values that are negative in the dependent variable while taking into account non negative values. Let equal and/or $>300 \mathrm{~kg} / \mathrm{year} /$ person be denoted by T. $Q_{l}$ is a censored dependent variable that is presented as follows:

$$
\mathrm{E}\left[Q_{l} / H\right]=\Phi(\Delta) T+(1-\Phi(\Delta))(\Delta H+\sigma \lambda(\varrho))
$$

where $=\frac{(\mathrm{T}-\Delta \mathrm{H})}{\sigma}, \lambda(\mathrm{C})=\frac{\phi(\Delta H)}{(1-\Phi(\mathrm{H}))} . \Phi($.$) and \phi($.$) are standard normal distribution and$ density functions, respectively (Greene, 2003). $\mathrm{T}$ is a vector for $300 \mathrm{~kg}$ per person per years. $\lambda()=\frac{\phi(\Delta H)}{(1-\Phi(H))}$ is called an inverse mills ratio. A Mill ratio indicates how one unit change in exogenous variables alters the latent dependent variable. Marginal effect of a Tobit model is represented as follows:

$$
\frac{d E\left[Q_{l}{ }^{*} / H\right]}{d H}=\Delta \Phi((L \mathrm{H}-\mathrm{T}) / \sigma)=\left\{1-\lambda(\varrho)\left[\frac{\Delta H}{\sigma}\right]+\lambda(\Delta \varrho)\right\}=1
$$

where $T$ is a censoring point that has a numeracy of $300 \mathrm{~kg} /$ person/year. For censored data, the marginal effects are as follows:

$$
\frac{\mathrm{dE}\left(\mathrm{Q}_{l}\right)}{\mathrm{dH}}=\Phi\left(\frac{[\Delta H / \sigma]}{\Delta}\right)
$$

Furthermore, we derive the log likelihood expression for the censored regression model as:

$$
\begin{array}{r}
\ln L=-\frac{1}{2} \sum_{\gtrsim 275 k g}(\ln (2 \pi))+\ln \left(\sigma^{2}\right)+\left(\left(Q_{l}-\Delta H\right)^{2}\left(1 / \sigma^{2}\right)\right)+\sum_{\ll 275 k g} \ln (1- \\
\left.\Phi\left(\frac{\Delta H}{\sigma}\right)\right)
\end{array}
$$

where $\sum($.$) is a sum over the non censored and censored observations. From the theory$ above, we derive and illustrate our empirical model as follows: 


$$
Q_{l}=H_{l}+\zeta M_{l}+\kappa_{l}
$$

where $\mu$ and $\zeta$ are vectors of unknown parameters. Other variables are as described above in equation 12. Our censored Tobit model considers two categories. Firstly, there is information on both independent variables and dependent variable. Secondly, it has limited information on dependent variable and is specified as follows:

$$
Q_{l}(.)=\left\{\begin{array}{c}
0, Q_{l}{ }^{*}=Q_{l}=\mu H_{l}+\zeta M_{l}+\kappa_{l}<T \\
\text { actualnumber, } Q_{l}{ }^{*}=Q_{l}=\mu H_{l}+\zeta M_{l}+\kappa_{l} \gtrsim T
\end{array}\right.
$$

where $Q_{l}{ }^{*}$ is equal to zero [0] if food available at the house is less that $300 \mathrm{~kg} /$ person/year (T). On the other hand, $Q_{l}{ }^{*}$ is equal to the actual food quantity if food is at least 300 $\mathrm{kg} /$ person/year. Expression 13 can also be expressed as follows:

$$
\begin{aligned}
& \mathrm{P}(\text { censored })=\mathrm{P}\left(\mathrm{Q}_{\mathrm{l}}^{*}<T\right)=\Phi\left(\frac{\mathrm{T}-\Delta \mathrm{H}}{\sigma}\right)=1-\Phi\left(\frac{\mathrm{T}-\Delta \mathrm{H}}{\sigma}\right) \\
& \mathrm{P}(\text { uncensored })=1-\Phi\left(\frac{\Delta \mathrm{H}-\mathrm{T}}{\sigma}\right)=\Phi\left(\frac{\Delta \mathrm{H}-\mathrm{T}}{\sigma}\right)
\end{aligned}
$$

Data used in this analysis was collected from a household survey conducted among randomly sampled households from 26 villagesin Chikhwawa district, southern Malawi.

Table 1. Definition of Variables used in this paper

\begin{tabular}{llll}
\hline Variables & Measurements & Variables & Measurements \\
\hline Gender & $1=$ Female; $0=$ Male & Drought & $1=$ Yes; $0=$ No \\
Education & Years & Floods & $1=$ Yes; $0=$ No \\
Labour & Man-day & IGA-income & Malawi Kwacha \\
Land size & Acres & Irrigation farming & $1=$ Yes; $0=$ No \\
Income & Malawi Kwacha & Planting dates & $1=$ Yes; $0=$ No \\
Age & Years & Improved varieties & $\mathrm{Kg} /$ Acre \\
Extension & Number of visits & Local seeds & $\mathrm{Kg} /$ Acre \\
Rainfall & $1=$ Increased; $0=$ Reduced & Crop diversification & $1=$ Yes; $0=$ No \\
Temperature & $1=$ Increased; $0=$ Reduced & Agroforestry & $1=$ Yes; $0=$ No \\
Pest outbreak & $1=$ Affected; $0=$ not affected & Climatic information & $1=$ Yes; $0=$ No \\
Fertilizer & Kg/Acre & Yield & $\mathrm{Kg} / \mathrm{Acre}$ \\
\hline
\end{tabular}

Empirical analysis was supported by participatory rural appraisals. Participatory rural appraisals were in the form of focus group discussions and key informants interview. Interviews included questions such as what are the roles of adaptation on household food security and food production. 


\section{RESULTS AND DISCUSSION}

\subsection{Household Socioeconomic Characteristics}

Household characteristics such as education, income and gender of the household head influence the level of understanding and application of any agricultural technology (Edris, 2003). Table 2 shows that females head about $41 \%$ and $47 \%$ of the households in both low and highland areas of Chikhwawa district, respectively. Conversely, Table 1 shows that males head $59 \%$ and $53 \%$ of the lowland and highland households. The mean age of household head in low and highland areas is 39 and 35, respectively. Accordingly, NSO (2008) found that household heads in Malawi are in the economically active group of 25 to 49 years. Table 2 show no substantial difference between low and highland household head level of education. Most household heads in the study area have reached primary school. The southern part of Malawi experiences high temperatures with Chikhwawa having higher than 25 degree Celsius throughout the year. Besides, southern Malawi receives very low annual rains (EAD, 2006).

Table 2. Household Characteristics between Low and Highland Households

\begin{tabular}{|c|c|c|c|c|c|c|c|c|}
\hline \multirow[t]{2}{*}{ Variable } & & \multicolumn{2}{|c|}{ Lowlands } & \multicolumn{2}{|c|}{ Highlands } & \multicolumn{3}{|c|}{ Pooled Sample } \\
\hline & & Mean & Std. E. & Mean & Std. E. & Mean & Std.E. & t-test \\
\hline \multirow[t]{2}{*}{ Gender } & Female & 41 & 0.035 & 47 & 0.053 & 43 & 0.029 & 1.019 \\
\hline & Male & 59 & 0.035 & 53 & 0.053 & 57 & 0.029 & \\
\hline \multicolumn{2}{|c|}{ Household head Age } & 39.29 & 0.997 & 34.66 & 1.426 & 37.837 & 0.826 & 1.315 \\
\hline \multicolumn{2}{|c|}{ Family Size } & 5.902 & 0.190 & 5.269 & 0.245 & 5.703 & 0.152 & 0.971 \\
\hline \multicolumn{2}{|c|}{ Labour (People>15yrs) } & 3.073 & 0.120 & 3.136 & 0.182 & 3.0928 & 0.100 & -0.294 \\
\hline \multicolumn{2}{|c|}{ HHD Education } & 3.784 & 0.260 & 4.652 & 0.382 & 4.057 & 0.216 & -1.483 \\
\hline Educ. & None(\%) & 28.35 & & 22.47 & & 26.50 & & \\
\hline \multirow[t]{3}{*}{ Levels } & Primary(\%) & 58.25 & & 62.92 & & 59.72 & & \\
\hline & Secondary & 12.37 & & 13.48 & & 12.72 & & \\
\hline & Tertiary(\%) & 01.03 & & 01.12 & & 01.06 & & \\
\hline \multirow{2}{*}{\multicolumn{2}{|c|}{$\begin{array}{l}\text { otal Land (acres) } \\
\text { Annual Income (MK) }\end{array}$}} & 1.703 & 0.069 & 1.429 & 0.098 & 1.617 & 0.057 & 1.122 \\
\hline & & 46202 & 3750 & 45468 & 6684 & 45971 & 3314 & 0.103 \\
\hline
\end{tabular}

Furthermore, Table 2 shows that $58 \%$ and $63 \%$ of the low and highland households have reached primary level. Besides, on average, a household in low and highland areas of Chikhwawa district has five members. The average household size in the study area is in line with NSO (2008) report that average household members in Chikhwawa are five. Additionally, the results revealed that low and highland areas have, on average, 1.7 acres ( $0.69 \mathrm{ha})$ and 1.4 acres ( $0.57 \mathrm{ha}$ ) of land, respectively. The mean value of household annual income for lowland households is MK 46,202 (US \$ 308) and highland households have MK45, 466 (US\$ 303). Nonetheless, there is no difference between low and highland household annual income at any level of significance.

\subsection{Contribution of Adaptation on Household Food Production}

In this paper, contributions of adaptation strategies on household food crop production were assessed using a Translog production function (Table 3). It is shown that the Log likelihood tests are significant and depict strong goodness of fit on household food production. Area of crop field significantly influences food production. Table 3 shows that crop fields that are in 
the highland areas are likely to reduce food production by $24 \%$. The results show that characteristics such as labour, income and land had significant contribution on food crop production.

Irrigation farming, income-generating activities, improved varieties, agroforestry and shifting planting dates influenced household food production in both low and highland areas. Results indicate that irrigation farming improved food production in both directions. For instance, a household that irrigated crops increased food production by $8 \%$ in lowland areas and reduced food production by $6 \%$ in highland areas. According to focus group discussions, it was reported that households easily engage in irrigation farming because of water availability. In highland areas, most households do not engage in irrigation farming due to lack of water for irrigating and the situation is very different in lowland areas.

It is shown that improved varieties positively enhanced household food production by $20 \%$ and $24 \%$ in low and highland areas, respectively. Improved varieties that are adopted in the study areas are locally known as kanyani (improved varieties) and kapire (local varieties). On the other hand, households grew local varieties. Through focus group discussions, it was reported households grew local varieties because they survive during harsh climatic and weather effects. Shifting plating dates reduced food production by $24 \%$ and $38 \%$ in low and highland areas. Focus group discussions reported that shifting crop-planting dates shrunk food production because of water shortages for crop development, growth and maturity. It was further pointed that abrupt discontinuity of rainfall affects the growth of crops, as crops need enough amount of water for them to grow and mature.

Furthermore, results in Table 3 show that agroforestry significantly boosts household food production by $2 \%$ and $49 \%$ among lowland and highland households. Focus group discussions reported that households adopt agro forestry practices to improve soil fertility and retain soil moisture during unfavourable temperatures. Considering the whole sample size, agroforestry has a negative effect on food production. Focus group discussions reported that agroforestry did not automatically increase production in the first years. It was suggested that there is a need of incorporating inorganic fertilizers in the field especially during initial years of adopting agroforestry practices. Accordingly, Ajayi et al. (2008) pointed out that agroforestry technologies require two to three years time lag for them to contribute significantly. It is also found that crop diversification substantially improved household production by $25 \%$ in lowland areas. Discussions with farming households indicated that diversified crops allow households harvest some food crop yield despite bad weather.

Income-generating activities (IGAs) substantially improve food production (Table 3). A household that engage in income generating activities, increased food production by $63 \%$ and $28 \%$ in low and highland areas, respectively. Focus group discussions reported that households venture into income generating activities to earn income that is used to buy improved varieties and pay hired labour for the next growing period. Consequently, households counterbalanced the effects droughts and floods through earnings from off farm income generating activities. Pangapanga et al., (2012) pointed out that positive effects of income generating activities on household crop production compels households to plough back IGAs' earning into farming activities. However, Pangapanga and Thangalimodzi (2012) highlighted the backfiring effect of IGAs on farming activities in the long run. 
Table 3. Translog production function estimates

\begin{tabular}{|c|c|c|c|c|c|c|}
\hline & Lowlanc & & Highlan & & Pooled & ample \\
\hline & Coef & Std Err & Coef & Std Err & Coef & Std Err \\
\hline Local seeds & $0.146^{*}$ & 0.049 & 0.025 & 0.050 & $0.064^{\star *}$ & 0.037 \\
\hline Hybrid seeds $(\mathrm{kg})$ & 0.678 & 0.717 & $0.14^{\star}$ & 0.018 & $0.621^{*}$ & 0.059 \\
\hline Fertilizer & 0.498 & 0.183 & 0.393 & 0.040 & 0.984 & 0.175 \\
\hline Labour & $0.469^{*}$ & 0.003 & 0.297 & 0.314 & $0.551^{* *}$ & 0.260 \\
\hline Land & $0.019^{*}$ & 0.000 & 0.799 & 1.148 & $0.071^{* *}$ & 0.038 \\
\hline IGA-Income & $0.633^{*}$ & 0.000 & $0.278^{*}$ & 0.113 & $0.581^{*}$ & 0.022 \\
\hline Irrigation farming & $0.076^{*}$ & 0.004 & 0.061 & 0.237 & $0.804^{*}$ & 0.157 \\
\hline Planting dates & $-0.242^{*}$ & 0.001 & $-0.37^{\star *}$ & 0.284 & $-0.50^{\star *}$ & 0.206 \\
\hline Improved varieties & $0.195^{\star *}$ & 0.026 & $0.240^{\star *}$ & 0.066 & 0.126 & 0.200 \\
\hline Crop diversification & $0.247^{*}$ & 0.002 & -0.439 & 0.469 & $0.223^{* *}$ & 0.130 \\
\hline Agroforestry & $0.019^{*}$ & 0.001 & $0.486^{*}$ & 0.232 & $-0.54^{\star *}$ & 0.219 \\
\hline Climatic Information & $0.169^{* *}$ & 0.096 & $0.184^{*}$ & 0.089 & $0.386^{*}$ & 0.065 \\
\hline Crop diversification_plot & $0.134^{*}$ & 0.003 & 0.040 & 0.070 & $0.128^{*}$ & 0.003 \\
\hline Agroforestry_plot & $0.038^{*}$ & 0.005 & $0.088^{*}$ & 0.028 & $0.006^{*}$ & 0.002 \\
\hline $\mathrm{A} 1(\mathrm{IV}-\mathrm{SPD})^{2}$ & -0.449 & 0.262 & -0.625 & 0.662 & 0.189 & 0.280 \\
\hline A2 (IV-IF) $)^{3}$ & $0.547^{* *}$ & 0.262 & 0.063 & 0.335 & 0.146 & 0.239 \\
\hline A3 (IF-IGA) ${ }^{4}$ & -0.276 & 0.262 & -0.136 & 0.664 & $0.335^{*}$ & 0.105 \\
\hline A4 (Cl-IV-IGA) ${ }^{5}$ & $0.266^{*}$ & 0.003 & $0.549^{*}$ & 0.252 & -0.214 & 0.234 \\
\hline A 5(IV-IGA-IF) ${ }^{6}$ & -0.238 & 0.262 & 0.610 & 0.688 & -0.137 & 0.238 \\
\hline A6 (IV-IGA-CD $)^{7}$ & 0.046 & 0.262 & $0.446^{*}$ & 0.043 & $0.551^{* *}$ & 0.260 \\
\hline Area(Highland=1) & & & & & $-0.24^{\star *}$ & 0.106 \\
\hline LR & 139.16 & & -55.89 & & 217.22 & \\
\hline Chi-Sq & $496^{*}$ & & $496^{*}$ & & $118^{*}$ & \\
\hline
\end{tabular}

From Table 3, it is depicted that irrigation of improved varieties (combination of improved varieties with irrigation farming) improved household food production. A household that grew improved varieties increased food production by $55 \%$ and $6 \%$ in low and highland areas, respectively. Focus group discussions pointed out that households are risk averse and combine a number of strategies in order to counteract the effects of climatic and weather variability. Furthermore, a mixture of IGAs with climatic information and improved varieties augmented household food production by $27 \%$ and $55 \%$ in low and highland areas, respectively. On the other hand, a combination of irrigation farming with income generating activities reduced household food production by $28 \%$ and $14 \%$ in low and highland areas, respectively due to competition over labour. Discussions with farmers revealed that household labour was divided between the irrigation and income generating activities.

\footnotetext{
${ }^{2}$ Improved Varieties(IV) * Shifting Planting Dates (SPD)

${ }^{3}$ Improved Varieties * Irrigation Farming (IF)

${ }^{4}$ Irrigation Farming* Income Generating Activities (IGA)

${ }^{5}$ Climatic Information (Cl) * Improved Varieties * Income Generating Activities

${ }^{6}$ Improved Varieties * Irrigation Farming * Income Generating Activities

${ }^{7}$ Improved Varieties * Income Generating Activities * Crop Diversification (CD)
} 


\subsection{Contributions of Adaptation on Household Food Security}

The paper analyzed the contribution of adaptation strategies on household food security and/or availability. A Normalized Tobit Model evaluated contributions of adaptation strategies on household food security. Table 4 presents results of a Normalized Tobit Model.

Table 4. Normalized tobit regression estimates

\begin{tabular}{|c|c|c|c|c|c|c|}
\hline & \multicolumn{2}{|l|}{ Lowland } & \multicolumn{2}{|c|}{ Highland } & \multicolumn{2}{|c|}{ Pooled Sample } \\
\hline & $d y / d x$ & Std. E. & $d y / d x$ & Std. E. & $d y / d x$ & Std. E. \\
\hline Gender of HHD & 0.136 & 0.356 & 0.042 & 0.551 & 0.139 & 0.306 \\
\hline Education of HHD & 0.227 & 0.214 & 0.159 & 0.376 & 0.149 & 0.172 \\
\hline Labour & 0.008 & 0.118 & 0.035 & 0.173 & -0.051 & 0.100 \\
\hline Land holding size & $0.078^{*}$ & 0.020 & $0.042^{* *}$ & 0.027 & 0.057 & 0.168 \\
\hline IGA-income & $0.239 *$ & 0.033 & $0.198^{*}$ & 0.028 & $0.237^{*}$ & 0.023 \\
\hline Irrigation farming & $0.242^{*}$ & 0.090 & $0.185^{*}$ & 0.082 & $0.209^{*}$ & 0.070 \\
\hline Planting date & $-0.206^{*}$ & 0.102 & -0.104 & 0.084 & -0.089 & 0.078 \\
\hline Improved varieties & $0.235^{\star}$ & 0.187 & 0.047 & 0.084 & 0.095 & 0.080 \\
\hline Crop diversification & $0.264^{*}$ & 0.083 & 0.052 & 0.059 & $0.138^{*}$ & 0.066 \\
\hline Agroforestry & $-0.479^{*}$ & 0.185 & $-0.151^{*}$ & 0.073 & $-0.246^{*}$ & 0.082 \\
\hline Climatic information & $0.267^{*}$ & 0.103 & $0.179^{* *}$ & 0.111 & $0.373^{*}$ & 0.074 \\
\hline Crop diversification_Plot & $0.194^{*}$ & 0.006 & $0.006^{*}$ & 0.007 & $0.187^{*}$ & 0.005 \\
\hline Agroforestry Plot & 0.010 & 0.012 & 0.007 & 0.004 & 0.004 & 0.005 \\
\hline A1(IV-SPD) & -0.213 & 0.110 & -0.123 & 0.105 & -0.159 & 0.079 \\
\hline A2 (IV-IF) & $0.204^{*}$ & 0.137 & 0.007 & 0.119 & $-0.171^{*}$ & 0.087 \\
\hline A3 (IR-IGA) & -0.209 & 0.213 & $-0.408^{\star *}$ & 0.255 & $0.185^{\star *}$ & 0.101 \\
\hline A4 (CI-IV-IGA) & $0.487^{*}$ & 0.195 & 0.033 & 0.124 & 0.125 & 0.110 \\
\hline A5 (IV-IGA-IF) & $-0.716^{*}$ & 0.220 & $-0.158^{*}$ & 0.028 & $0.290^{*}$ & 0.098 \\
\hline Area(Highland=1) & & & & & $-0.331^{*}$ & $0.108^{*}$ \\
\hline & -1213.23 & & -570.06 & & -1803.9 & \\
\hline Chi-sq & $27.45^{\star}$ & & $17.78^{*}$ & & $-30.21^{*}$ & \\
\hline
\end{tabular}

Table 4 shows that land has significant influence on household food security. It is portrayed that there is a strong goodness of fit to capture the food security scenario at household level as indicated by the Chi-square. Area of crop field affected household food security by $33 \%$. Land increased food availability/year/ person by $9 \%$ and $4 \%$ in low and highland areas. The paper found that factors such as education and gender did not have substantial effect on household food security in both areas at any significant level. In this paper, irrigation farming, crop diversification (CD) and income generating activities significantly influence household food security in both areas. Irrigation farming improved food availability by $24 \%$ and $19 \%$ in low and highland areas, respectively. Focus group discussions explained that households that engaged in irrigation farming had more produce, which translated into more food available to the household members.

Crop Diversification enhanced food availability by $26 \%$ and $5 \%$ in low and highland areas, respectively. According to focus group discussions, it was reported that crop diversification increased a number of food products of the households. Households that diversify their crops have advantage to harvest some food even when one crop failed to do better. In other 
words, when all crops do better, the household had an added advantage over the combine contribution of diversified production on food security. Similarly, income-generating activities positively boosted food availability. Households that engaged in off farm income generating activities increased food availability by $24 \%$ and $20 \%$ in low and highland areas, respectively. Focus group discussions pointed out that households supplemented own production with food purchased from the market. It was further elaborated that income from IGAs helped economically access food from the local markets.

On the other hand, shifting crop-planting dates reduced household food availability. Households that shifted their crop planting dates reduced food security by $21 \%$ and $10.4 \%$ in low and highland areas, respectively. Focus group discussions reported that reduced food availability at household level was because of reduced amount of food harvested from lateplanted gardens because crops do not have the required amount of rainwater. Besides, agroforestry practices reduced household food security. Households that practised agroforestry technologies reduced food availability by $58 \%$ in the paper areas. This is contrary to a paper by Ajayi et al. (2008) that found that agroforestry improved food availability by more than 2 times. However, Ajayi et al. (2008) emphasized for an appropriate agroforestry environment for farmers to derive benefits from agroforestry. Focus group discussion cited that from experience agroforestry did not automatically translate into high food availability due to time lag involved. In other words, focus group discussions suggested for inorganic fertilizer incorporation in agroforestry practised farming activities.

On the ground, it is reported through focus group discussions that households simultaneously adopt alternative adaptation strategies to cushion themselves from food insecurity exasperated by climatic change. From Table 8 , the paper findings depicted that combination of irrigation farming with improved varieties increased food availability by $20 \%$ and $7 \%$ in low and highland areas, respectively. On the other hand, mixture of income generating activities with irrigation farming and improved varieties reduced food availability by $72 \%$ and $16 \%$ in low and highland areas, respectively. Focus group discussions reported that combination of some adaptation strategies resulted into reduced food availability because of resource diversion (labour, income) between the strategies.

\section{CONCLUSION}

This paper has examined the contributions of various droughts and floods related adaptation strategies on household food production and food security. Based on results from the Translog production function, the paper concludes that adaptation strategies such as crop diversification, irrigation farming and income generating activities have positive and significant contribution on household food production. For instance, growing of improved varieties increases household production by $20 \%$ and $24 \%$ in low and highland areas, respectively. Furthermore, combination of improved varieties and irrigation farming improved food production by $55 \%$ and $6 \%$ in low and highland areas, respectively. On the other hand, households that shift planting dates experience a reduction in food production by $24 \%$ and $37 \%$ among both low and highland areas, respectively. Besides, it is found that a mixture of irrigation farming and income-generating activities reduces household food production by $14 \%$ in the study area. Empirical results from a normalized and censored Tobit model establish that irrigation enhances food availability by $24 \%$ and $19 \%$ inlow and highland areas, respectively. However, combination of irrigation farming with income generation activities shrunk food availability by $21 \%$ and $41 \%$ in low and highland areas due to labour diversion. Similarly, shifting planting dates reduces household food availability by $21 \%$ and $10 \%$ in both low and highland areas, respectively. It is therefore concluded that adaptation 
strategies have very interesting policy implications in terms of both household crop production and food security. In this paper, it is therefore suggested that decisions on household food production and availability have to mainstream droughts and floods related adaptation.

\section{COMPETING INTERESTS}

Authors have declared that no competing interests exist.

\section{REFERENCES}

Action Aid International. (2006). Droughts and floodsandSmalholder Farmers in Malawi. Lilongwe. Malawi. http://actionaid.org.uk/doc_lib/malawi_climate_change.

Aggarwal, P.K., Baethegan, W.E., Cooper, P., Gommes, R., Lee, B., MeinkE H., Rathore L.S., Sivakumar, M.V.K. (2010). Managing Climatic Risks to Combat Land Degradation and Enhance Food security. Procedia Environmental Sciences, 1, 305312.

Aigner, D.J., Loveli, C.A.K., Schmidt, P. (1977). Formulation \& estimation of stochastic production function models. Journal of Econometrics, 6, 21-37.

Ajayi, O.C., Akinnifesi, F.K., Sileshi, G., Chakeredza, S., Mn'gomba, S., Nyoka, I., Chineke T. (2008). Local solutions to global problems: the potential of agroforestry for climate change adaptation and mitigation in Southern Africa. Lilongwe, Malawi.

Akpalu, W., Hassan, R.M., Ringler, C.(2008). Climate variability and maize yield in South Africa. Environment and Production Technology Division. IFPRI Paper 00843.

Bauer, P.W. (1990). Recent Development in the Econometric Estimation of Frontiers. Journal of Econometrics, 46, 39-56.

Bravoureta, B.E., Rieger, L. (1991). Dairy farm efficiency measurement using stochastic frontiers and neoclassical duality. American journal of Agricultural Economics.

Chavas, J.P., Cox, T.L. (1988). A non parametric analysis of agricultural technologies. Americal Journal of Agricultural Economics, 70, 303-310.

Edriss, A.K. (2003). Passport to research methods. International Publishers, Las Vegas, USA.

Environmental Affairs Department (EAD). (2006). National adaptation programme for action. Ministry of Natural Resources and Environmental Affairs, Lilongwe, Malawi.

Famine early Warning Network-USAID. (2010). Malawi food updates, Lilongwe, Malawi.

Farrell, M.J. (1957). The measurements of production efficiency. Journal of Statistics \& Social Science, 120, 253-281.

Gomani, M., Bie, S., Mkwambisi, D. (2008). Climate change and rural livelihoods in Malawi. Final Report. The Royal Norwegian Embassy, Lilongwe, Malawi.

Government of Malawi (GoM). (2004). Annual economic report. Ministry of Development Planning and Cooperation. Lilongwe. Malawi.

Government of Malawi (GoM). (2008). Annual economic report. Ministry of Development Planning and Cooperation. Lilongwe. Malawi

Hassan, R., Nhemachena, C. (2008). Determinants of African farmers' strategies for adapting to climatic change: Multinomial choice analysis. African Journal of Agricultural and Resource Economics, 2(1), 83-104 .

International Monetary Fund. (2010). World Economic outlook. Recovery, Risk and Rebalancing. IMF Publication Services. Washington DC, USA. 
Langyintuo, A., Mekuria, M. (2008). Assessing the influence of neighborhood effects on the adoption of improved agricultural technologies in developing agriculture. African Journal of Agricultural Economics, 2(2), 152-169.

Molua, E.L., Mlambi, C.M. (2008). The impact of climate change on agriculture in Cameroon, policy research working paper 4364, development research group, sustainable rural and urban development team. Washington DC: The World Bank.

Nangoma, E. (2007). National adaptation strategy to droughts and floodsimpacts: fighting climatic change: human solidarity in a divided world. UNDP, Malawi.

National Statistical Office (NSO). (2008). Population and household census. Zomba, Malawi.

National Statistical Office (NSO). (2012). The Third Integrated Household Survey (IHS3). Zomba, Malawi.

Nhemachena, C. (2009). Agriculture and future climate dynamics in Africa: Impacts and adaptation options. University of Pretoria. South Africa.

Pangapanga, P.I., Jumbe, C.B.L., Thangalimodzi, L. (2012). Household choices and droughts and floodsadaptation in southern Malawi. LAP. Lambert Publisher, USA.

Pangapanga, P.I., Jumbe, C.B.L., Kanyanda, S., Thangalimodzi, L. (2012). Unraveling strategic choices towards droughts and floods' adaptation in Southern Malawi, International Journal of Disaster Risk Reduction, http://dx.doi.org/10.1016/j.ijdrr.2012.08.002.

Paul, K., Thurlow, J., Servester, D. (2010). Drought and floods in Malawi: Assessing the economy wide effects. International Food Policy Research Insitute (IFPRI) Discussion Paper 00962. Lilongwe, Malawi.

Tchale, H., Bohn, E., Armas, E., Kambambe, S. (2004). Malawi and Southern Africa: Climatic Variability and Economic Performance, Washington DC. USA. http://www.odi.org.uk/resources/details.asp?id=3658\&title=malawi-climate-change.

Tchale, H., Sauer, J. (2006). Soil Fertility Management and Agricultural Productivity in Malawi, Bunda College. Lilongwe, Malawi.

World Bank. (2010). The economics of adaptation to climate change synthesis report. Washington DC. USA.

(c) 2012 Pangapanga et al.; This is an Open Access article distributed under the terms of the Creative Commons Attribution License (http://creativecommons.org/licenses/by/3.0), which permits unrestricted use, distribution, and reproduction in any medium, provided the origin al work is properly cited. 